\title{
Safety Assessment of a New Pigmented Safflower Seed Coat (A82) by a Feeding Study on Rat
}

\author{
Soraya Karami ${ }^{1}$, Mohammad R. Sabzalian ${ }^{1}$, Layasadat Khorsandi ${ }^{2 *}$, Mehdi Rahimmalek ${ }^{\mathbf{1}}$. \\ ${ }^{1}$ Dept. of Agronomy and Plant Breeding, College of Agriculture, Isfahan University of Technology, Isfahan 84156- \\ 83111, Iran; ${ }^{2}$ Cell \& Molecular Research Center, Faculty of Medicine, Ahvaz Jundishapur University of Medical \\ Sciences, Ahvaz, Iran.
}

\begin{abstract}
Safflower (Carthamus tinctorius L.) is an annual herbaceous plant, cultivated mainly for the seed which is used for edible oil extraction and bird feeding. This study was designed to evaluate the safety of a new pigmented variety of safflower (A82) seeds. The results showed that oral administration of A82 seeds significantly increased the body weight of male rats in a dose-dependent manner ( $p<0.05)$. Biochemical tests showed that A82 seeds significantly increased the serum levels of AST (Aspartate aminotransferase) ( $p<0.05)$, slightly reduced the serum levels of ALT (Alanine aminotransferase) and significantly reduced ALP ( $p<0.05)$ levels in a dose dependent manner. BUN (Blood Urea Nitrogen) and $\mathrm{Cr}$ (Creatinine) were not significantly changed in A82 seed treated groups. Also, testosterone levels were not significantly changed by administration of different doses of A82. However, Johnson scoring showed slightly decrease in experimental groups. No organ weight or histological changes were observed in liver, kidney, spleen, heart and brain of A82 seed treated animals. These results indicate that A82 seeds have not any toxic effects in Wistar rats. Future studies are required to clarify the exact mechanism by which A82 seeds alter AST levels and body weight in rat.
\end{abstract}

Key words: Safflower black seed, Herbal medicine, Food safety, Toxicity

\footnotetext{
*Author for correspondence: Khorsandi_cmrc@yahoo.com
} 


\section{INTRODUCTION}

There are 15 species of the genus Carthamus L., which belong to the Compositae (Asteraceae) plant family. These self and cross pollinating species are found as either annual or perennial, and grow in the wild or are cultivated around the world $\left.{ }^{1}\right]$. Six species are native to Iran, of which $C$. tinctorius is cultivated in different parts and $C$. oxyacanthus grows in the wild in the central and western areas of the country $\left[{ }^{2}\right]$. Traditionally, the crop was cultivated for its flowers, which were used as coloring and flavoring ingredients in foods, making dyes and in medicine. The water extract of this flower could be used instead of saffron because it is more economical $\left[{ }^{3,4}\right]$. In recent times, the plant is mainly cultivated for its seed. The seed (achene) of this species is composed of three main parts: seed coat (pericarp), germ and cotyledons. The varying color patterns usually seen on the seed coat is genetically controlled by one or two loci $\left[^{5}\right]$. The seed coat in the cultivated safflower is either white or cream. Sabzalian et al. $\left[^{6}\right]$ discovered a new pattern of black seed coat color in wild safflower, $C$. oxyacanthus. This trait was transferred via hybridization from the accession of $C$. oxyacanthus with black seeds to the cultivated safflower, and a strong relationship was found between seed coat color and resistance to the safflower fly (Acanthiophilus helianthi). Also, 1000-seed weight of black seeds was higher than the white one. ${ }^{6}$ Seed oil suitable for human consumption and industrial purposes was also extracted from the wild safflower, indicating that the seed coat color has no negative effect on seed oil content and quality $\left[^{7}\right]$.

High levels of various phenolic compounds such as lignin and flavonoids have been detected in seed of safflower $\left[{ }^{8}\right]$. The relationship between seed color with total phenolic and flavonoid contents, as reported by Shen et al. $\left[{ }^{9}\right]$ and Thaddi et al. $\left[{ }^{10}\right]$, may increase the popularity of plant varieties with pigmented seeds in food and medicinal industries in the future $\left[{ }^{9-14}\right]$. The colored seeds may also have lethal effects on some insect pests like the safflower fly which feeds on safflower seeds. This insect poses a great threat in safflower seed cultivation in many countries around the world such as Asia by causing severe decrease of crop yield $\left[{ }^{15}\right]$.

In Iran, seed yield loss of safflower through insect attack has been estimated in the range of $30-70 \%\left[^{6}\right]$. Although, chemical controls may be effective to manage the safflower fly damage, this approach is not always satisfactory because of the polyphagous nature of this insect $\left.{ }^{16}\right]$, expensive pesticides and the adverse effect of pesticides on some beneficial insects. Additionally, there are several reports of the positive correlations between pesticide exposure and some cancers like brain, breast and prostate cancers $\left[{ }^{17}\right]$. It may be possible that host plant-resistance is an ecofriendly approach for pest management and simultaneous environmental conservation $\left[{ }^{18,19}\right]$.

Colored seeds may also contain some anti-nutritional properties for non-insect consumers $\left[{ }^{20}\right]$ and therefore, before releasing any variety of safflower with modified seed coat color, it is of great importance to identify its nutritional consequences compared to white coated varieties. In spite of beneficial properties of black-seeded genotype (named A82), safety evaluation before routine use of this seed as food additive is necessary. Therefore, the present study was undertaken to evaluate the probable toxicological effects of the new pigmented variety of safflower seed, A82, in rat. 


\section{MATERIALS AND METHODS}

\section{Preparation of the seed suspension}

The plant materials included the black seeds of a novel safflower breeding line (named A82), a white-seeded safflower genotype derived from Kooseh land race (named C111) and the Canadian genotype of Ac-Stirling (Fig. 1). The breeding line A82 was the result of interspecific hybridization between C111, the female parent, with a black-seeded genotype of wild safflower (C. oxyacanthus), and following advanced generations of back crossing and selfing, a uniform population of safflower with black seed coat was obtained (Sabzalian MR, unpublished). Seeds were harvested from a field trial in which genotypes were planted in a randomized complete block design at the Research Farm of Isfahan University of Technology, Isfahan $\left(32^{\circ} 32^{\prime} \mathrm{N}\right.$ and $51^{\circ} 32^{\prime} \mathrm{E}, 1630 \mathrm{~m}$ asl). A random sample of seeds was ground and mixed with distilled water to prepare suspensions of 30,60, 180 and $240 \mathrm{mg} / \mathrm{kg}$ to be used as treatment doses.
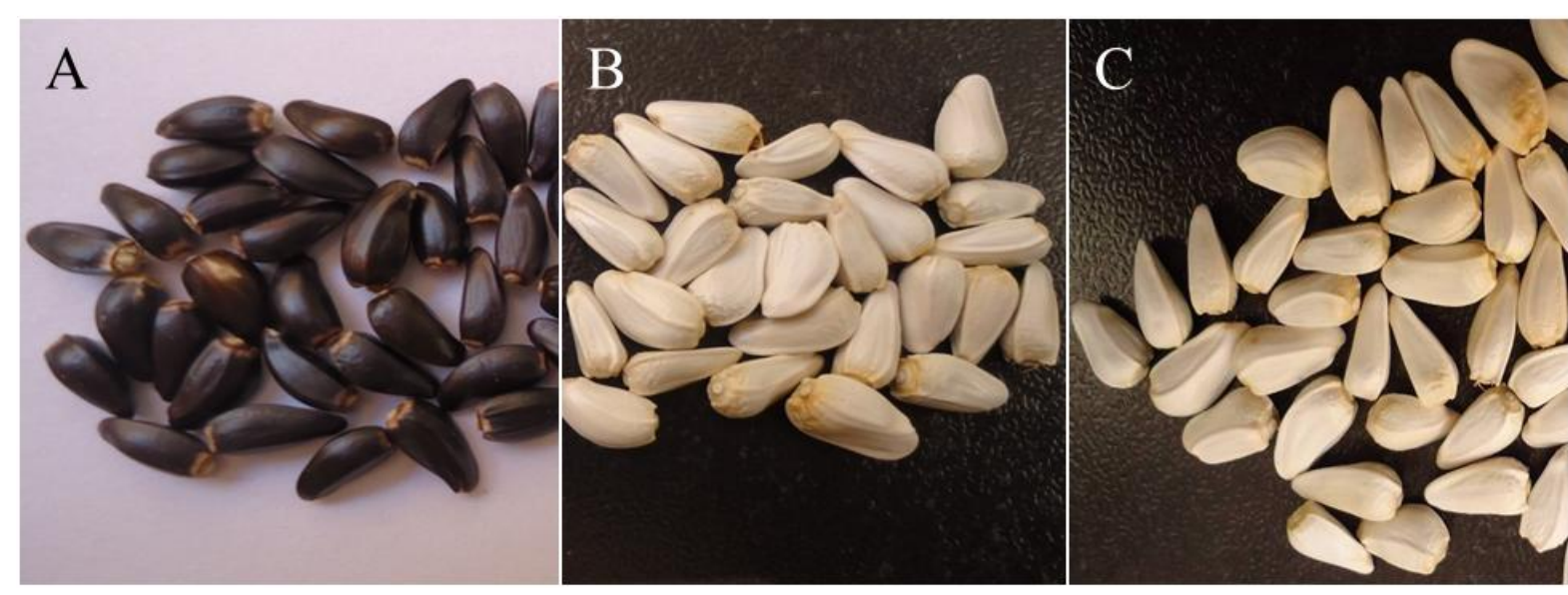

Figure 1. A82 as breeding line of safflower with black seed coat (A) and cultivated genotypes of C111 (B) and AcStirling with white seed coat (C).

\section{Animals}

In this study, 78 healthy adult male Wistar rats (8-10 weeks old, 160-180 g) obtained from Ahvaz Jundishapur University of Medical Sciences, Experimental Research Center, were used. The study was approved by the ethics committee of Jundishapur University and carried out following the guidelines provided. The animals were kept under standard laboratory conditions $(12 \mathrm{~h}$-dark and $12 \mathrm{~h}$ - light cycle, relative humidity of $50 \pm 5 \%$ and $22 \pm 3^{\circ} \mathrm{C}$ ) for at least one week before the experiment and conditions were maintained until the end of the experiment. Animal cages were kept clean, while commercial food (pellet) and water were provided ad libitum.

\section{Experimental design}

The animals were randomly divided into three treatment groups of 24 and a control group with 6 animals. Each treatment group was divided into four subgroups of six animals each. At the beginning of the experiment, the animals were weighted. The control group received $0.2 \mathrm{~mL}$ normal saline by gavage for 5 weeks. The experimental groups received a suspension from one of A82, C111 and Ac-Stirling seeds $\left[{ }^{21}\right]$ through a feeding needle (oral administration) in doses of 30, 60, 180 and $240 \mathrm{mg} / \mathrm{kg} /$ day for 5 weeks. Changes in body weight, behavior and possible appearance of symptoms in the rats were carefully recorded every day after each treatment. One day after the last administration, blood sampling was performed, and 
the rats were finally sacrificed by cervical dislocation under ether anesthesia, and liver, kidneys, heart, spleen, brain and testicles from each animal were removed quickly and weighed. The testicles from each animal were then fixed in Bouin's solution and the other tissue samples were immediately transferred into $10 \%$ formalin for histological assessments.

\section{Measurement of serum biochemical markers}

Collected blood samples were centrifuged to obtain the serum. The serum enzyme levels, including serum alanine aminotransferase (ALT), aspartate aminotransferase (AST) and alkaline phosphatase (ALP) as marker enzymes of hepatotoxicity and blood urea nitrogen (BUN) and creatinine ( $\mathrm{Cr}$ ) as markers of nephrotoxicity, were assessed using commercially available kits (Sigma).

\section{Testosterone assay}

Serum and testicular testosterone concentration was measured by the enzyme-linked immunoassay (Testosterone ELISA Test Kit) method as previously described $\left[{ }^{22}\right]$.

\section{Histological assessments}

All tissue samples were embedded in paraffin and sections with 4-5 $\mu \mathrm{m}$ thickness were made using microtome. Then, sections were stained hematoxylin-eosin (H \& E) and observed under a light microscope to observe histological changes. Six microscopic stained slides per animal were examined for signs of histological assessments. Maturity of the germinal epithelium was graded by using the modified Johnsen's scoring method. This is a simple way for assessing the spermatogenesis. By using a x40 magnification, 150 tubules per animal were evaluated and each tubule was given a score ranging from 1 to 10 . The tubules having complete inactivity were scored as 1 and those with maximum activity (at least five or more spermatozoa in the lumen) were scored as $10\left[{ }^{23}\right]$. Three observers, who were blinded to the control and experimental groups, analyzed the sections independently.

\section{Statistical analysis}

Statistical analysis was performed using SPSS software v. 19.0. Comparisons between multiple groups were evaluated using one-way analysis of variance (ANOVA), followed by least significance difference (LSD) test. The data were presented as means \pm standard deviation (SD), and $p<0.05$ was considered as the level of statistical significance.

\section{RESULTS}

\section{Body and organ weight}

No animal was found dead or in a moribund state during the experiment. There were also no treatment related clinical signs such as lethargy, ataxia, etc. In experimental groups, dose dependent significant increases $(p<0.05)$ in the body weight were observed. The increase in body weight in A82 seed treatment was significantly higher than the white seed treated animals $(\mathrm{p}<0.05)$. Ac-Stirling seed groups showed more elevation in body weight in comparison to $\mathrm{C} 111$ seed treated animals. The safflower seeds had no effect on the organ weights of liver, kidney, spleen, heart, brain and testis. These results are reported in Table 1 .

\section{Biochemical markers}

ALT levels in the experimental groups were slightly decreased in comparison with those in the control group. AST levels in the experimental groups were significantly increased in comparison to the control group ( $\mathrm{p}<0.05$ ). ALP levels in the experimental groups were significantly decreased in a dose dependent manner. These 
alterations were more prominent in A82 seed treated animals especially at the dose of $240 \mathrm{mg} / \mathrm{kg}$. BUN and $\mathrm{Cr}$ levels in experimental groups were similar to the control group. There were no significant differences in biochemical tests among the three experimental groups. These results are shown in Table 2.

Table 1. Body and organ weight (g) for control and experimental groups.

\begin{tabular}{llllllll}
\hline Groups & Body & liver & kidney & Testis & Brain & Spleen & Heart \\
\hline Control & $196.7 \pm 5.9$ & $10.5 \pm 1.2$ & $2.2 \pm 0.3$ & $1.7 \pm 0.2$ & $2.3 \pm 0.4$ & $0.77 \pm 0.3$ & $1.2 \pm 0.2$ \\
A82: $30 \mathrm{mg} / \mathrm{kg}$ & $243.4 \pm 3.1^{*}$ & $10.6 \pm 1.1$ & $2.2 \pm 0.2$ & $1.8 \pm 0.2$ & $2.2 \pm 0.3$ & $0.81 \pm 0.1$ & $1.3 \pm 0.3$ \\
A82: $60 \mathrm{mg} / \mathrm{kg}$ & $246.8 \pm 4.0^{*}$ & $10.7 \pm 1.3$ & $2.3 \pm 0.4$ & $1.8 \pm 0.3$ & $2.3 \pm 0.2$ & $0.82 \pm 0.2$ & $1.3 \pm 0.1$ \\
A82: $180 \mathrm{mg} / \mathrm{kg}$ & $249.7 \pm 5.0^{*}$ & $10.2 \pm 1.3$ & $1.9 \pm 0.3$ & $1.7 \pm 0.3$ & $2.1 \pm 0.4$ & $0.75 \pm 0.3$ & $1.4 \pm 0.3$ \\
A82: $240 \mathrm{mg} / \mathrm{kg}$ & $271.9 \pm 4.6^{*}$ & $10.3 \pm 1.1$ & $1.9 \pm 0.2$ & $1.6 \pm 0.2$ & $2.2 \pm 0.5$ & $0.77 \pm 0.2$ & $1.1 \pm 0.1$ \\
C111: $30 \mathrm{mg} / \mathrm{kg}$ & $215.3 \pm 2.1^{*} \#$ & $10.1 \pm 1.4$ & $2.2 \pm 0.3$ & $1.7 \pm 0.4$ & $2.3 \pm 0.2$ & $0.73 \pm 0.1$ & $1.4 \pm 0.1$ \\
C111: $60 \mathrm{mg} / \mathrm{kg}$ & $220.5 \pm 3.0^{* \#}$ & $10.4 \pm 1.1$ & $1.9 \pm 0.2$ & $1.9 \pm 0.2$ & $2.3 \pm 0.3$ & $0.84 \pm 0.3$ & $1.2 \pm 0.3$ \\
C111: $180 \mathrm{mg} / \mathrm{kg}$ & $223.2 \pm 2.7^{*} \#$ & $10.7 \pm 1.2$ & $2.3 \pm 0.2$ & $1.7 \pm 0.2$ & $2.3 \pm 0.4$ & $0.75 \pm 0.2$ & $1.3 \pm 0.2$ \\
C111: $240 \mathrm{mg} / \mathrm{kg}$ & $235.8 \pm 2.5^{*} \#$ & $10.6 \pm 1.3$ & $1.8 \pm 0.3$ & $1.6 \pm 0.3$ & $2.1 \pm 0.3$ & $0.78 \pm 0.1$ & $1.5 \pm 0.1$ \\
Ac-Stirling: $30 \mathrm{mg} / \mathrm{kg}$ & $212.7 \pm 2.5^{*} \#$ & $10.1 \pm 1.3$ & $2.3 \pm 0.3$ & $1.8 \pm 0.2$ & $2.4 \pm 0.2$ & $0.74 \pm 0.3$ & $1.1 \pm 0.4$ \\
Ac-Stirling: $60 \mathrm{mg} / \mathrm{kg}$ & $222.2 \pm 3.1^{* \#}$ & $10.6 \pm 1.1$ & $1.9 \pm 0.3$ & $1.7 \pm 0.2$ & $2.2 \pm 0.5$ & $0.75 \pm 0.2$ & $1.4 \pm 0.3$ \\
Ac-Stirling: $80 \mathrm{mg} / \mathrm{kg}$ & $227.4 \pm 3.3^{*} \#$ & $10.3 \pm 1.2$ & $2.1 \pm 0.2$ & $1.6 \pm 0.3$ & $2.1 \pm 0.3$ & $0.81 \pm 0.1$ & $1.5 \pm 0.2$ \\
Ac-Stirling: $240 \mathrm{mg} / \mathrm{kg}$ & $243.5 \pm 5.3^{*} \#$ & $10.2 \pm 1.3$ & $1.9 \pm 0.2$ & $1.8 \pm 0.2$ & $2.3 \pm 0.2$ & $0.82 \pm 0.2$ & $1.3 \pm 0.1$ \\
\hline Vals & &
\end{tabular}

Values are expressed as mean $\pm \mathrm{SD}$ for 6 rats. ${ }^{*} p<0.05, \# p<0.05, *$ and $\#$ symbols indicate comparison to control and A82 groups, respectively.

Table 2. Biochemical tests for the control and experimental groups.

\begin{tabular}{lccccc}
\hline Groups & AST (U/L) & ALT (U/L) & ALP (U/L) & BUN (mg/L) & Cr $(\mathbf{m g} / \mathbf{L})$ \\
\hline Control & $139.5 \pm 26.2$ & $68.2 \pm 3.5$ & $819.5 \pm 38.2$ & $21.3 \pm 1.5$ & $0.53 \pm 0.1$ \\
A82: $30 \mathrm{mg} / \mathrm{kg}$ & $157.3 \pm 28.2^{*}$ & $67.2 \pm 2.4$ & $614.3 \pm 30.0^{*}$ & $17.0 \pm 1.3$ & $0.51 \pm 0.1$ \\
A82: $60 \mathrm{mg} / \mathrm{kg}$ & $156.0 \pm 23.1^{*}$ & $67.5 \pm 2.1$ & $621.8 \pm 30.7^{*}$ & $16.9 \pm 1.2$ & $0.52 \pm 0.2$ \\
A82: $180 \mathrm{mg} / \mathrm{kg}$ & $160.2 \pm 28.1^{*}$ & $66.6 \pm 2.0$ & $539.8 \pm 25.3^{*}$ & $16.8 \pm 1.4$ & $0.50 \pm 0.1$ \\
A82: $240 \mathrm{mg} / \mathrm{kg}$ & $166.7 \pm 24.0^{*}$ & $63.5 \pm 2.5$ & $493.6 \pm 21.9^{*}$ & $15.7 \pm 1.3$ & $0.49 \pm 0.1$ \\
C111: $30 \mathrm{mg} / \mathrm{kg}$ & $153.5 \pm 30.2^{*}$ & $69.5 \pm 3.5$ & $662.0 \pm 23.2^{* \#}$ & $17.0 \pm 1.2$ & $0.52 \pm 0.1$ \\
C111: $60 \mathrm{mg} / \mathrm{kg}$ & $161.5 \pm 25.2^{*}$ & $68.5 \pm 3.5$ & $654.5 \pm 29.5^{* \#}$ & $16.8 \pm 1.3$ & $0.48 \pm 0.2$ \\
C111: $180 \mathrm{mg} / \mathrm{kg}$ & $162.0 \pm 27.0^{*}$ & $65.2 \pm 2.0$ & $617.5 \pm 24.1^{* \#}$ & $16.3 \pm 1.4$ & $0.51 \pm 0.1$ \\
C111: $240 \mathrm{mg} / \mathrm{kg}$ & $169.5 \pm 26.4^{*}$ & $62.0 \pm 1.4$ & $505.5 \pm 24.4^{* \#}$ & $15.9 \pm 1.5$ & $0.49 \pm 0.1$ \\
Ac-Stirling: $30 \mathrm{mg} / \mathrm{kg}$ & $151.3 \pm 31.0^{*}$ & $68.3 \pm 2.2$ & $656.1 \pm 29.9^{* \#}$ & $17.1 \pm 1.1$ & $0.52 \pm 0.1$ \\
Ac-Stirling: $60 \mathrm{mg} / \mathrm{kg}$ & $154.5 \pm 29.1^{*}$ & $67.0 \pm 1.2$ & $647.2 \pm 23.5^{* \#}$ & $16.2 \pm 1.3$ & $0.52 \pm 0.1$ \\
Ac-Stirling: $80 \mathrm{mg} / \mathrm{kg}$ & $162.0 \pm 21.3^{*}$ & $65.1 \pm 3.1$ & $605.0 \pm 27.0^{* \#}$ & $16.9 \pm 1.0$ & $0.51 \pm 0.1$ \\
Ac-Stirling: $240 \mathrm{mg} / \mathrm{kg}$ & $170.5 \pm 29.2^{*}$ & $64.5 \pm 3.6$ & $516.5 \pm 26.3^{* \#}$ & $15.9 \pm 1.1$ & $0.49 \pm 0.1$
\end{tabular}

Values are expressed as mean \pm SD for 6 rats. ${ }^{*} p<0.05, \# p<0.5, *$ and \# symbols indicate comparison to the control and A82 groups, respectively.

Testosterone assay

Serum and testicular testosterone concentrations in the experimental groups were not significantly changed in comparison with those in the control group. These results are reported in Table 3. 
Table 3. Johnsen's scoring and testosterone concentration for the control and experimental groups.

\begin{tabular}{lccc}
\hline Groups & Johnsen Scoring & $\begin{array}{c}\text { Testis testosterone } \\
(\mathbf{n g} / \mathbf{g})\end{array}$ & $\begin{array}{c}\text { Serum testosterone } \\
(\mathbf{n g} / \mathbf{m l})\end{array}$ \\
\hline Control & $9.2 \pm 0.2$ & $4.5 \pm 0.2$ & $1.7 \pm 0.2$ \\
A82: $30 \mathrm{mg} / \mathrm{kg}$ & $9.0 \pm 0.7$ & $4.6 \pm 0.1$ & $1.6 \pm 0.2$ \\
A82: $60 \mathrm{mg} / \mathrm{kg}$ & $8.9 \pm 0.5$ & $4.2 \pm 0.2$ & $1.3 \pm 0.2$ \\
A82: $180 \mathrm{mg} / \mathrm{kg}$ & $9.1 \pm 0.9$ & $4.4 \pm 0.3$ & $1.9 \pm 0.2$ \\
A82: $240 \mathrm{mg} / \mathrm{kg}$ & $8.5 \pm 0.7$ & $5.1 \pm 0.4$ & $1.5 \pm 0.2$ \\
C111: $30 \mathrm{mg} / \mathrm{kg}$ & $9.4 \pm 0.8$ & $4.9 \pm 0.4$ & $1.8 \pm 0.2$ \\
C111: $60 \mathrm{mg} / \mathrm{kg}$ & $8.9 \pm 0.9$ & $4.7 \pm 0.2$ & $1.3 \pm 0.2$ \\
C111: $180 \mathrm{mg} / \mathrm{kg}$ & $9.1 \pm 0.7$ & $4.6 \pm 0.1$ & $1.6 \pm 0.2$ \\
C111: $240 \mathrm{mg} / \mathrm{kg}$ & $8.2 \pm 0.8$ & $4.7 \pm 0.3$ & $1.5 \pm 0.2$ \\
Ac-Stirling: $30 \mathrm{mg} / \mathrm{kg}$ & $8.9 \pm 0.4$ & $4.3 \pm 0.3$ & $1.5 \pm 0.2$ \\
Ac-Stirling: $60 \mathrm{mg} / \mathrm{kg}$ & $8.8 \pm 0.5$ & $5.2 \pm 0.1$ & $1.4 \pm 0.3$ \\
Ac-Stirling: $80 \mathrm{mg} / \mathrm{kg}$ & $9.0 \pm 0.2$ & $4.1 \pm 0.2$ & $1.8 \pm 0.5$ \\
Ac-Stirling: $240 \mathrm{mg} / \mathrm{kg}$ & $8.2 \pm 0.3$ & $4.6 \pm 0.5$ & $1.7 \pm 0.4$ \\
\hline V & & &
\end{tabular}

Values are expressed as mean \pm SD for 6 rats.

\section{Histological changes}

Under light microscope, liver lobular structures in the control group were clear and regular, and single layer of hepatocytes arranged around the central vein in a radical pattern. Normal architecture of liver was observed in all experimental groups.

Light microscope evaluation of kidneys in the control group showed normal morphology of renal parenchyma with well-defined glomeruli and tubules. In experimental groups, kidneys showed normal appearance similar to the control group.

Normal architecture of the seminiferous tubules and intact germinal epithelium were observed in the control group. In experimental groups, at the dose of $240 \mathrm{mg} / \mathrm{kg}$, a few numbers of seminiferous tubules showed poor spermatogenesis and the mean Johnsen's score was slightly less than the control group. The results of the mean Johnsen's score are shown in Table 3. Other tissues including heart, spleen and brain showed appearance similar to the control group.

\section{DISCUSSION}

Plant species have an array of complex chemical ingredients which can affect the whole body or a specific organ and system. Some of the chemical constituents are mild and safe, even when applied in large doses, while others may be toxic in low doses or when taken continuously. The present study demonstrated that 5 weeks administration of pigmented (A82) and non-pigmented safflower seeds (Ac-Stirling and C111) increased the body weight of Wistar rats in a dose dependent manner. This finding is in contrast to the results of Mohan et al. $\left[{ }^{24}\right]$ who reported that the average gain in body weight was significantly reduced in chickens fed with diets containing 23,35 and $48 \%$ of white seeds of safflower. Similarly, Kwon et al. $\left[{ }^{25}\right.$ ] demonstrated that administration of white seeds of safflower for 13 weeks reduced the body weight of F344 rats. On the other hand, Koyama et al. $\left[{ }^{26}\right]$ showed that consumption of white-seeded safflower did not change the body weight in healthy human. On the other hand, in the present study, organ weights did not change, indicating that safflower seed may increase appetite and consequently increase body mass. The effect of safflower seeds on appetite is yet to be investigated. 
There is no documented information on the oil content of A82. However, two other varieties of Ac-Stirling and C111 have 34.00 and $30.20 \%$ oil content in seeds, respectively $\left[{ }^{7}\right]$. The higher seed oil content in Ac-Stirling compared to C111 may justify its greater effect on increasing the body weight in this study. Since A82 has more effect on body weight, it is possible that it possesses more oil content than the white seeds.

As reported in the results, there was significant increase in the AST levels in experimental groups while no significant change was seen in the ALT levels in these animals. However, there were no histological changes in liver. Apart from being found in liver, the AST enzyme is also found in skeletal muscles of heart, skeletal muscle, kidneys, brain, and red blood cells. In cases involving these tissue injuries, the AST is released into the blood stream $\left[{ }^{27}\right]$. However, in this study, organ weights and histology of heart muscles, kidney and brain were normal. In liver and serum, total AST activity corresponds to two isoenzymatic activities, which are mitochondrial and cytosolic in nature. About $80 \%$ of AST activity in liver is contributed by the mitochondrial isoenzyme $\left[{ }^{28}\right]$. Thus, A82 may seed affect mitochondria and induces AST leakage from the hepatocytes.

A82, as well as white seeded safflower genotypes, significantly reduced the level of ALP. ALP as a hepatotoxicity marker enzyme is localized in the bile canalicular pole of hepatocytes. In a diseased liver, this bile duct is often blocked, keeping fluid within the liver. Thus, ALP accumulates and eventually escapes into the blood stream $\left[{ }^{28}\right]$. Therefore, safflower seeds may improve liver function. Li et al. $\left.{ }^{29}\right]$ reported that safflower red pigment has protective effect against $\mathrm{CCl}_{4}$-induced acute liver injury in mice. Zhang et al. $\left[{ }^{30}\right]$ also demonstrated that hydroxysafflor yellow had beneficial effects on hepatic fibrosis.

The present study showed that the levels of BUN and $\mathrm{Cr}$ were lower in the treatment groups compared to the control. The serum levels of BUN and $\mathrm{Cr}$ as marker enzymes of nephrotoxicity were the main indices which reflected renal injury. Histological renal changes were not observed in all experimental groups, and this observations support the results of the biochemical test. This is while, Liu et al. $\left[{ }^{31}\right]$ reported that yellow A, the main segment of C. tinctorius yellow pigment, extracted from flowers, induces a slight nephrotoxicity in rats.

In this study, Johnsen scores in A82 and white seed-treated groups were slightly reduced, especially at the higher doses. Variations in the Johnsen's scoring might have resulted not only from a direct effect of safflower seed on germ cell death, but also from alterations of the Sertoli cells. Nevertheless, testosterone levels in all groups, indicated that there was no toxicity effect of safflower seeds on Leydig cells. Mirhosseini et al. $\left.{ }^{32}\right]$ showed that aqueous extract of safflower at a dose of 200 $\mathrm{mg} / \mathrm{kg}$ had toxic effects on mouse testicular tissue and significantly reduced spermatogenesis. There are already a few reports on the possible toxicological effects of various parts of safflower on laboratory animals. Nobakht et al. $\left[{ }^{33}\right]$ and Liu et al. $\left[{ }^{31}\right]$ respectively reported that the flowers had toxic effects on brain and renal tissues. Namjoo et al. $\left[{ }^{34}\right]$ demonstrated that the extract of safflower was toxic and caused hepatic, renal and brain tissue damages in mice.

Since genotype A82 genotype with black seed coat color was produced from C111 genotype (with white seed coat color and as female parent) through advanced generations of back crossing and selfing, they are considered as near isogenic lines in plant breeding point of view. This means that unlike the Canadian line of AcStirling, they have approximately the same genetic background. Therefore, it could be concluded that significant differences observed between the black-seeded A82 and white-seeded C111 in terms of body weight and ALP enzyme, possibly come from their discrimination regarding seed coat color. On the other hand, no significant 
difference between the two white- seeded genotypes (Ac-Stirling and C111) could support unimportant effect of genetic background on the studied traits.

\section{CONCLUSIONS}

Resistance to the safflower fly is one of the criteria to release safflower varieties and hybrids for cultivation in the fly affected areas. However, resistant varieties like "A82", with a new pattern of seed coat color, should avoid negative nutritional consequences on possible consumers. It seems that the new breeding line with black seed coat (A82) has no toxic effects on Wistar rats. In histological assessments, liver tissue was normal while AST levels were significantly increased in experimental groups. However, ALP and ALT levels in these animals were decrease. Future studies are required to clarify the reason of AST elevation by safflower seeds. There was no evidence of toxicity effect of A82 seeds in kidneys and other vital organs. However, slight testicular damage was observed at higher dosage of A82 seeds, hence more investigations need to be done to confirm reproduction safety of the breeding line. Also, future studies are required to clarify the mechanism by wich A82 seeds affect the body mass because the increase in body weight may be an interesting effect in the poultry industry.

\section{REFERENCES}

1-Vilatersana R, Susanna A, Garcia-Jacas N, Garnatje T. Generic delimitation and phylogeny of the Carduncellus-Carthamus complex (Asteraceae) based on ITS sequences. Plant Syste Evol. 2000; 221(1): 89-105.

2-Dittrich M, Petrak F, Rechinger KH, Wagenitz G. Compositae III-Cynareae. In: Rechinger KH, editor. Flora Iranica. Graz; 1979. pp. 139-468.

3-Hiramatsu M, Takahashi T, Komatsu M, Kido T, Kasahara Y. Antioxidant and neuroprotective activities of Mogami-benibana (safflower, Carthamus tinctorius Linne). Neurochem Res. 2009; 34(4): 795-805.

4-Emongor V. Safflower (Carthamus tinctorius L.) the underutilized and neglected crop: a review. Asian J Plant Sic. 2010; 9: 299-306.

5-Ramanamurthy GV. Relationships of cultivated safflower (Carthamus tinctorius L.) to the wild species C.oxyacantha MB. PhD thesis, University of California, Davis; 1964.

6-Sabzalian MR, Saeidi G, Mirlohi A, Hatami B. Wild safflower species (Carthamus oxyacanthus): A possible source of resistance to the safflower fly (Acanthiophilus helianthi). Crop Prot. 2010; 29(6): 550-555.

7-Sabzalian MR, Saeidi G, Mirlohi A. Oil content and fatty acid composition in seeds of three safflower species. J Am Oil Chem Society. 2008; 85(8): 717-721.

8-Kim EO, Lee KT, Choi SW. Chemical comparison of germinated and ungerminatedsafflower (Carthamus tinctorius) seeds. J Korean Soc Food Sci Nutr. 2008; 37(9): 11621167.

9-Shen Y, Jin L, Xiao P, Lu Y, Bao J. Total phenolics, flavonoids, antioxidant capacity in rice grain and their relations to grain color, size and weight. J Cereal Sci. 2009; 49(1): 106111.

10- Thaddi BN, Nallamilli MN. Estimation of total bioactive compounds in pigmented and non-pigmented genotypes of Sorghum (Sorghum bicolor (L.) Moench). Int J Adv Res Sci Technol. 2014(2); 3: 86-92.

11- Ahuja U, Ahuja SC, Chaudhary N, Thakrar R. Red rices-past, present and future. Asian Agr-Hist. 2007; 11(4): 291-304.

12- Chung HS, Shin JC. Characterization of antioxidant alkaloids and phenolic acids from anthocyanin-pigmented rice (Oryza sativa cv. Heugjinjubyeo). Food Chem. 2007; 104(4): 1670-1677. 
13- Finocchiaro F, Ferrari B, Gianinetti A, Dall'Asta C, Galaverna G, Scazzina F, et al. Characterization of antioxidant compounds of red and white rice and changes in total antioxidant capacity during processing. Mol Nutr Food Res. 2007; 51(8): 1006-1019.

14- Jang S, Xu Z. Lipophilic and hydrophilic antioxidants and their antioxidant activities in purple rice bran. J Agr Food Chem. 2009; 57(3): 858-862.

15- Talpur MA, Hussain T, Rustamani MA, Gaad MA, Ahmad M, Shakoori AR. Relative resistance of safflower varieties to safflower shoot fly, Acanthiophilus helianthi Rossi (Diptera: Tephritidae). Proc Pak Congr Zool. 1995; 15: 177-181.

16- Ashri A. Evaluation of the world collection of safflower, Carthamus tinctorius L. I. Reaction to several diseases and associations with morphological characters. Crop Sci. 1971; 11(2): 253-257.

17- Xu X, Dailey AB, Talbott EO, Ilacqua VA, Kearney G, Asal NR. Associations of serum concentrations of organochlorine pesticides with breast cancer and prostate cancer in US adults. Environ Health Persp. 2010; 118(1): 60-66.

18- Sharma HC. Host-plant resistance to insects in sorghum and its role in integrated pest management. Crop Prot. 1993; 12: 11-34.

19- Sharma HC, Ortiz R. Host plant resistance to insects: an eco-friendly approach for pest management and environment conservation. J Environ Biol. 2002; 23(2): 111-136.

20- Akande KE, Doma UD, Agu HO, Adamu HM. Major antinutrients found in plant protein sources: their effect on nutrition. Pak J Nut. 2010; 9(8): 827-832.

21- Bae CS, Park CH, Cho HJ, Han HJ, Kang SS, Choi SH, et al. Therapeutic effects of safflower (Carthamus tinctorius L.) seed powder on osteoporosis. Korean J Electron Microscopy. 2002; 32(3): 285-290.

22- Orazizadeh M, Khorsandi L, Absalan F, Hashemitabar M, Daneshi E. Effect of betacarotene on titanium oxide nanoparticles-induced testicular toxicity in mice. $J$ Assist Reprod Genet. 2014; 31(5): 561-568.

23- Orazizadeh M, Khorsandi LS, Hashemitabar M. Toxic effects of dexamethasone on mouse testicular germ cells. Andrologia. 2010; 42(4): 247-253.

24- Mohan L, Reddy CV, Rao PV, Siddiqui SM. Safflower meal as a protein source in broiler rations. Indian J Anim Sci. 1984; 54: 870-875.

25- Kwon E, Choi HJ, Kim YS, Lee SK, Lee KH, Chung JH, et al. Toxicological study of safflower seeds by thirteen-week repeated oral administration in F344 rats. Lab Anim Res. 2008; 24: 527-542.

26- Koyama N, Suzuki K, Furukawa Y, Arisaka H, Seki T, Kuribayashi K, et al. Effects of safflower seed extract supplementation on oxidation and cardiovascular risk markers in healthy human volunteers. Brit J Nutr. 2009; 101(4): 568-575.

27- Pol S, Nalpas B, Vassault A, Bousquet-Lemercier B, Franco D, Lacour B, Berthelot P, et al. Hepatic activity and mRNA expression of aspartate aminotransferase isoenzymes in alcoholic and nonalcoholic liver disease. Hepatology. 1991; 14(4):620-5.

28- Aragon G, Younossi ZM. When and how to evaluate mildly elevated liver enzymes in apparently healthy patients. Cleve Clin J Med. 2010; 77(3): 195-204.

29- Li XF, Li ZK, Wu SC, Ding H. Effect of safflower red pigment on acute liver injury induced by CC1-4 in mice. Modern Food Sci Technol. 2013; 7: 021.

30-Zhang Y, Guo J, Dong H, Zhao X, Zhou L, Li X, et al. Hydroxysafflor yellow A protects against chronic carbon tetrachloride-induced liver fibrosis. Eur J Pharmacol. 2011; 660(2): 438-444.

31- Liu Z, Li C, Li M, Li D, Liu K. The subchronic toxicity of hydroxysafflor yellow A of 90 days repeatedly intraperitoneal injections in rats. Toxicology. 2004; 203(1): 139-143.

32- Mirhoseini M, Mohamadpour M, Khorsandi L. Toxic effects of Carthamus tinctorius L. (Safflower) extract on mouse spermatogenesis. J Assist Reprod Gen. 2012; 29(5): 457-461.

33- Nobakht M, Fattahi M, Hoormand M, Milanian I, Rahbar N, Mahmoudian M. A study on the teratogenic and cytotoxic effects of safflower extract. J Ethnopharmacol. 2000; 73(3): 453-459.

34- Namjoo A, Rafieian M, Azizi S, Talebi-Juneghani A. Histopathologic effects of Carthamus tinctorius on the brain liver and kidney of the new born mice. J Shahrekord Univ Med Sci. 2010; 11(4): 38-45. 
Received: February 03, 2016; Accepted: July 14, 2016 